\title{
Role of parental and environmental characteristics in toddlers' physical activity and screen time: Bayesian analysis of structural equation models
}

Eun-Young Lee ${ }^{1}$, Kylie D. Hesketh², Ryan E. Rhodes ${ }^{3}$, Christina M. Rinaldi ${ }^{4}$, John C. Spence ${ }^{1}$ and Valerie Carson ${ }^{{ }^{*}}$

\begin{abstract}
Background: Guided by the Socialization Model of Child Behavior (SMCB), this cross-sectional study examined direct and indirect associations of parental cognitions and behavior, the home and neighborhood environment, and toddlers' personal attributes with toddlers' physical activity and screen time.
\end{abstract}

Methods: Participants included 193 toddlers (1.6 0.2 years) from the Parents' Role in Establishing healthy Physical activity and Sedentary behavior habits (PREPS) project. Toddlers' screen time and personal attributes, physical activityor screen time-specific parental cognitions and behaviors, and the home and neighborhood environment were measured via parental-report using the PREPS questionnaire. Accelerometry-measured physical activity was available in 123 toddlers. Bayesian estimation in structural equation modeling (SEM) using the Markov Chain Monte Carlo algorithm was performed to test an SMCB hypothesized model. Covariates included toddlers' age, sex, race/ethnicity, main type of childcare, and family household income.

Results: In the SMCB hypothesized screen time model, higher parental barrier self-efficacy for limiting toddlers' screen time was associated with higher parental screen time limiting practices $(\beta=0.451)$, while higher parental negative outcome expectations for limiting toddlers' screen time was associated with lower parental screen time limiting practices $(\beta=-0.147)$. In turn, higher parental screen time limiting practices was associated with lower screen time among toddlers $(\beta=-0.179)$. Parental modeling of higher screen time was associated with higher screen time among toddlers directly $(\beta=0.212)$ and indirectly through the home environment. Specifically, higher screen time among parents was associated with having at least one electronic device in toddlers' bedrooms $(\beta=0.146)$ and, in turn, having electronics in the bedroom, compared to none, was associated with higher screen time among toddlers $(\beta=0.250)$. Neighborhood safety was not associated with toddlers' screen time in the SEM analysis. No significant correlations were observed between the SMCB variables and toddlers' physical activity; thus, no further analyses were performed for physical activity.

Conclusions: Parents and their interactions with the home environment may play an important role in shaping toddlers' screen time. Findings can inform family-based interventions aiming to minimize toddlers' screen time. Future research is needed to identify correlates of toddlers' physical activity.

Keywords: Screen time limits, Parental modeling, Barrier self-efficacy, Outcome expectations, Bayesian theorem, Socialization model of child behavior

\footnotetext{
* Correspondence: vlcarson@ualberta.ca

${ }^{1}$ Faculty of Kinesiology, Sport, and Recreation, University of Alberta,

Edmonton, AB T6G 2H9, Canada

Full list of author information is available at the end of the article
} 


\section{Background}

Accumulating evidence suggests that physical activity has favorable effects, whereas screen-based sedentary behavior or screen time (e.g., television [TV] viewing) has detrimental effects on the health and well-being of children in the early years (birth to 4 years) [1-3] and school-aged children and youth (5-17 years) [4,5]. Given that physical activity and screen time patterns in the early years tend to persist into later childhood and adolescence [6,7], it is imperative that healthy active lifestyles are established early. However, recent prevalence estimates in a representative sample of Canadian children in the early years [8] indicate that $62 \%$ meet physical activity recommendations, $24 \%$ meet screen recommendations, and collectively $15 \%$ meet both recommendations within the new Canadian 24-Hour Movement Guidelines for the Early Years [9]. Therefore, identifying the key correlates of health-enhancing behavioral patterns of regular physical activity and minimal screen time during these formative years is of great importance.

It is well established that parents have an overarching influence on children's physical activity and screen time participation in the early years. Specific parenting practices may facilitate (e.g., parental modeling, parental support) or limit (e.g., TV viewing time rules) children's behaviors [10-12]. Parents also create a home environment that shapes and reinforces physical activity and screen time. For example, parents have direct control over what types of physical activity equipment or electronics are available in the home [13]. In addition, characteristics of neighborhoods where families live may also assist in enabling or disabling physical activity and screen time [14, 15]. However, to the authors' knowledge, no study has investigated the interplay between individual, familial, and environmental correlates and their combined associations with physical activity and screen time among children of the early years.

Theories provide structure for understanding the correlates of behavior. However, few behavioral theories or models focus specifically on children's behavior [16-18]. The Socialization Model of Child Behavior (SMCB) $[17,19]$ is one such model that incorporates the environment (e.g., neighborhood safety, availability of electronic devices/physical activity equipment at home), parental cognitions (e.g., parental positive/negative outcome expectations for supporting physical activity and limiting screen time) and behaviors (e.g., parental physical activity and screen time), and children's cognition/personal attributes (e.g., children's activity temperament) as correlates of children's behavior (e.g., physical activity, screen time). The model postulates that the correlates of behavior reciprocally interact with each other. The model also proposes direct and indirect associations between correlates and children's behaviors. Specifically, parental behaviors, children's cognitions or personal attributes, and the environment are thought to be directly associated with children's behaviors. In addition, parental cognitions are thought to be associated with children's behaviors indirectly through parental behaviors and the environment. No studies have used the full SMCB to guide the examination of correlates of children's physical activity and screen time.

Though the SMCB has not specifically been tested before, a number of reviews have examined the individual correlates of physical activity and/or screen time in the early year age group [12, 20-23]. However, the majority of evidence is focused on preschool-aged children (4-5 years) with little attention given to younger children [24-26]. Toddlerhood (12-35 months) is an optimal period for targeted interventions as most children become ambulatory and are being introduced to regular screen time during the ages of 2 to 3 years [22, 27]. Given the rapid growth and development during early childhood, intervention targets needed for toddlers may be different from those of preschoolers, and therefore interventions may need to be adapted to match the appropriate developmental level.

The purpose of this study was to examine direct and indirect associations of the home and neighborhood environment, parental cognitions and behavior, and toddlers' personal attributes with toddlers' physical activity and screen time (see Fig. 1). Specifically, it was hypothesized that (1) the neighborhood environment would be associated with toddlers' physical activity and screen time directly and indirectly through parental behavior and the home environment; (2) parental cognitions would be associated with toddlers' physical activity and screen time indirectly through parental behavior and the home environment; and (3) activity temperament would be associated with toddlers' physical activity and screen time directly and indirectly through the home environment. In addition, it was hypothesized that parental cognitions and parental behavior would have the strongest direct and indirect associations with toddlers' physical activity and screen time.

\section{Methods \\ Participants}

Data was sourced from the baseline time point (October, 2014 to September, 2015) of the Parents' Role in Establishing healthy Physical activity and Sedentary behavior habits (PREPS) project. Participants were recruited from four large local health centers in socioeconomically diverse neighborhoods in Edmonton, Canada during children's 18-month immunization appointments. Families were eligible to participate in the PREPS project if: (1) toddlers were walking, and (2) a parent was able to speak and read English. Of the 491 eligible families, a total of 257 agreed to participate in the study (participation rate: 52\%). The remaining 234 declined to participate due to the following reasons: busy schedules/lack of time/fatigue $(n=74)$, no interest $(n=64)$, parental perception that their child would not wear the 


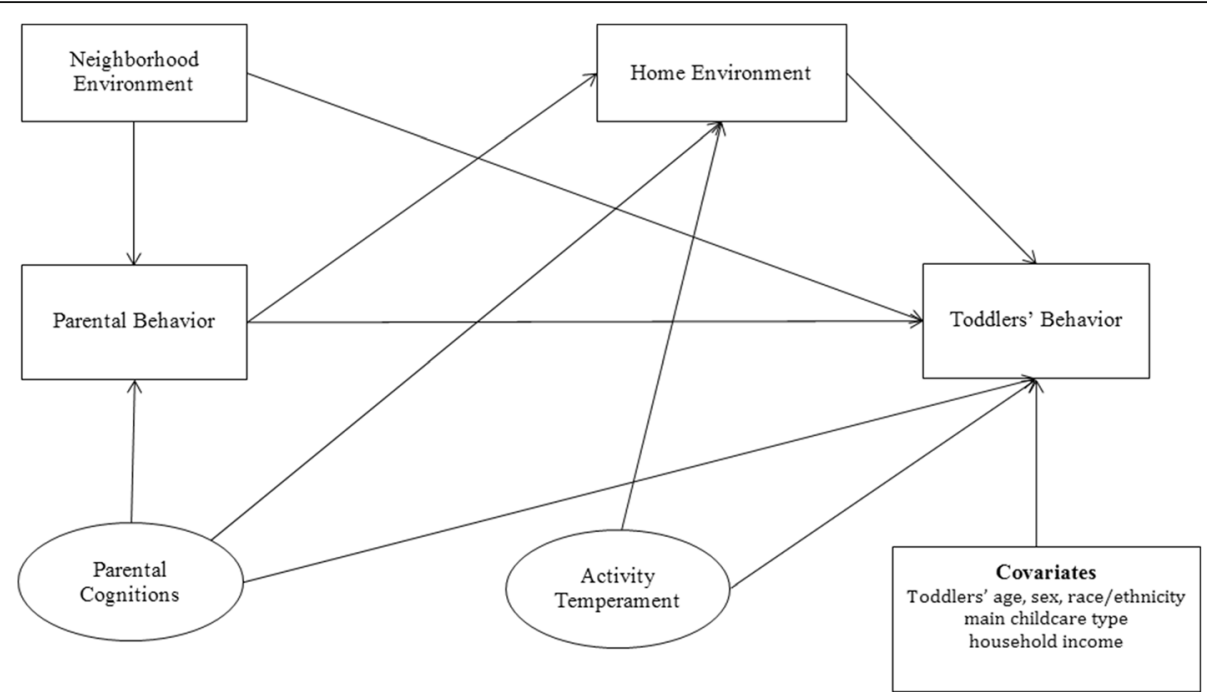

Fig. 1 A hypothesized model explaining the associations between parental cognitions, parental behavior, and the home and neighborhood environment on toddlers' screen time. Note: Ovals represent latent constructs and rectangles represent measured variables

accelerometer belt $(n=60)$, travel/illness/moving away $(n=20)$, or a parent not being present at the time of data collection $(n=16)$.

\section{Procedures}

During the 15-min waiting period required after children's immunizations, research staff asked eligible and participating families to complete a consent form and the PREPS questionnaire. Missing data were minimized by checking questionnaires for completeness and following up with families when needed. Participating families were also provided an accelerometer at the immunization appointment for their toddler to wear on the right hip for seven consecutive days, except for nighttime sleep and water-based activities (e.g., swimming, bathing). A pre-paid courier return envelope and written instructions were also provided. A midweek reminder was sent to participating parents about the continuous wear of their toddler's accelerometer. Informed written consent was provided by each participating parent, and ethics approval was granted by the University of Alberta Human Research Ethics Board. Detailed information about the PREPS project is described elsewhere $[19,28]$.

\section{Measures}

The PREPS questionnaire captured demographic information as well as physical activity and screen time information for each construct of the SMCB. The questionnaire was informed by a pilot study and through review of the literature [19]. Detailed descriptions of the variables and items of the PREPS questionnaire as well as the corresponding psychometric properties have been published previously [19]. Some variables were specific to toddlers' physical activity or screen time and other variables applied to both.

\section{Children's behavior}

Toddlers' physical activity and screen time were the variables assessed with the children's behavior construct of the SMCB. Toddlers' physical activity was objectively measured in 15-s epochs using waist-worn ActiGraph wGT3X-BT (ActiGraph Corp, Pensacola, FL, USA) accelerometers. Non-wear time was defined as $\geq 80$ consecutive 15 -s intervals of zero counts (equivalent to $\geq 20 \mathrm{~min}$ of consecutive zero counts). Based on previous reliability estimates, toddlers with $\geq 4$ days of valid data with $\geq 1440$ total 15 -s intervals (i.e., $\geq 6$ h of wear time) were included in the analysis $[24,29]$. Daytime naps were assumed to be included in non-wear time. Light-intensity physical activity (LPA) was defined as 25-420 counts/15-s epoch and moderate- to vigorous-intensity physical activity (MVPA) was defined as $>420$ counts/15-s epoch $[25,30]$. Minutes per day of LPA and MVPA were calculated by dividing the number of 15-s intervals by four and then dividing by the total number of valid days. Minutes per day of total physical activity (TPA) was then calculated by summing minutes per day of LPA and MVPA. Wear time standardized variables were used in all analyses by obtaining the residual values calculated from regressing the physical activity variables on wear time [31]. Previous research has reported strong criterion validity of the accelerometer against direct observation for measuring physical activity in toddlers $(r=0.66-0.82)$ [32, 33].

Toddlers' screen time was subjectively measured via parental-report using four items adopted from previous studies [34, 35] that were modified from the Canadian Health Measures Survey [36]. Specifically, parents were asked to report on the average hours and minutes per day on weekdays and weekend days for: (1) TV, videos, or DVDs on a TV, computer, or portable device, and (2) video/computer games on electronic devices (e.g., a 
learning laptop, leapfrog leapster, computer, laptop, tablet, cell phone, the internet, Playstation, or XBOX). Total TV viewing and video/computer game use were computed using weighted averages for weekday and weekend responses (i.e., [weekday*5 + weekend*2]/7). Weighted minutes per day of each variable were then summed to generate total screen time. Good one-week test-retest reliability was shown for the screen time questions (Intraclass correlation $[\mathrm{ICC}]=0.82)[19]$.

\section{Children's personal attributes}

Toddlers' activity temperament was the variable assessed within the children's personal attributes construct of the SMCB for physical activity and screen time. Activity temperament included 12 items from the short form of Early Childhood Behavior Questionnaire [37]. Parents were asked to report the frequency of specific behaviors their toddler engaged in (e.g., "sit quietly", "seem full of energy even in the evening", "toss about in bed", "run through the house") within six different contexts (i.e., while bathing, when participating in daily activities, during sleep, when playing outdoor with other children, while being dressed or undressed, while playing indoors) on a 7-point scale ranging from "never" to "always". After reverse coding four items, responses from the 12 items were averaged; higher average estimates represented a higher "predilection for movement" [38]. Good one-week test-retest reliability $(\mathrm{ICC}=0.78)$ and good internal consistency $(\alpha=0.79-0.84)$ at two time points were shown for the activity temperament questions [19].

\section{Parental cognitions}

Barrier self-efficacy (i.e., one's belief about one's ability to complete a task while overcoming difficulties [39]) and outcome expectations (i.e., a belief about the likelihood of the behavior leading to a specific outcome [40]) for supporting toddlers' physical activity and limiting screen time were the variables assessed within the parental cognitions construct of the SMCB. Barrier self-efficacy for supporting toddlers' physical activity included 7 items primarily based on a previous study [41]. All items were rated on an 8-point scale ranging from "not confident" to "completely confident". Outcome expectations for supporting toddlers' physical activity included 8 items (5 items reflecting positive outcome expectations and 3 items reflecting negative outcome expectations) primarily based on a previous study [41]. All items were rated on an 8-point scale ranging from "no chance" to "certain to happen". Responses for barrier self-efficacy, positive outcome expectations, and negative outcome expectations were averaged within the respective scales. Higher average estimates represented higher confidence for overcoming barriers related to supporting toddlers' physical activity and higher positive or negative perceived consequences for supporting toddlers' physical activity. Moderate one-week test-retest reliability and moderate to good internal consistency at two time points were shown for the barrier self-efficacy (ICC $=0.62 ; \alpha=0.84-0.86$ ), positive outcome expectations (ICC $=0.62 ; \alpha=0.90-0.95$ ), and negative outcome expectations (ICC $=0.55 ; \alpha=0.61-0.68$ ) for supporting physical activity questions [19].

Barrier self-efficacy for limiting screen time included 3 items primarily based on previous studies [35, 41, 42]. All items were rated on an 8-point scale ranging from "not confident" to "completely confident". Outcome expectations for limiting screen time included 7 items (3 items reflecting positive outcome expectations and 4 items reflecting negative outcome expectations) primarily based on a previous study [43]. All items were rated on an 8point scale ranging from "no chance" to "certain to happen". Responses for barrier self-efficacy, positive outcome expectations, and negative outcome expectations were each averaged. Higher average estimates represented higher confidence for overcoming barriers to limiting toddlers' screen time and higher positive or negative perceived consequences of limiting toddlers' screen time, respectively. Moderate one-week test-retest reliability and good internal consistency at two time points were shown for the barrier self-efficacy (ICC $=0.64 ; \alpha=0.86$ ), positive outcome expectations ( $\mathrm{ICC}=0.62 ; \alpha=0.92-0.93$ ), and negative outcome expectations (ICC $=0.64 ; \alpha=0.74-0.77$ ) for limiting screen time questions [19].

\section{Parental behavior}

Modeling of physical activity and support for physical activity, and modeling of screen time and limits on screen time were the variables assessed within the parental behavior construct of the SMCB. Modeling of physical activity included 6 items on physical activity adopted from the short form of the International Physical Activity Questionnaire [44]. Parents were asked to report the duration and frequency of vigorous intensity physical activity (VPA), moderate intensity physical activity (MPA), and walking during the last 7 days. Time spent in VPA, MPA, and walking activity were weighted by the energy expended for each activity to produce MET-minutes of PA values per week (i.e., 8.0*VPA minutes*VPA days + 4.0*MPA minutes*MPA days $+3.3^{*}$ walking minutes"walking days). Support for physical activity included 4 items based on previous studies $[19,45,46]$. All items were rated on an 8-point scale ranging from "never" to "daily". Higher estimates represented more frequent parental support for physical activity. Moderate to good one-week test-retest reliability were shown for the physical activity modeling $(\mathrm{ICC}=0.67)$, and physical activity support questions $(\mathrm{ICC}=0.59$ ), and good internal consistency at two time points were also shown for the physical activity support question $(\alpha=0.74-0.77)$ [19].

Modeling of screen time included 3 items adopted from a national survey in Canada [36]. Parents were asked to report on the duration of their weekly screen viewing in 
the past 3 months by hours and minutes. Total TV viewing, computer use, and video game use were averaged and then summed to generate parents' total screen time per day (i.e., [TV viewing hours* $60+\mathrm{TV}$ viewing minutes] $/ 7$ + [computer use hours" $60+$ computer use minutes] $/ 7$ + [video game use hours"60 + video game use minutes]/7). Parents' screen time data were presented as minutes per day by dividing the values by seven to be consistent with the toddlers' data. Limits on screen time included a single item primarily based on a previous study [47]. This single item was rated on an 8-point scale ranging from "never" to "daily". Higher estimates represented more frequent limiting of toddlers' screen time to zero minutes per day. Moderate to good one-week test-retest reliability were shown for the screen time modeling $(\mathrm{ICC}=0.76)$ and limits questions (kappa $=0.57)$ [19].

\section{Home environment}

Yard space and the availability of physical activity equipment at home were the variables assessed within the home environment construct of the SMCB for physical activity. The yard space variable included a single item and the availability of physical activity equipment at home included 10 items based primarily on a previous study [47]. Parents were asked to report on how big their yard is on a 6-point scale ranging from "no yard" to "a large yard (1/4 acre block or larger)". Availability of physical activity equipment was assessed by asking parents to report on types of toys and equipment available at home for their toddler to engage in physical activity (i.e., balls, basketball hoop, bats/racquets/ golf clubs, climbing equipment, gardening tolls, play house, pool or beach toys, tricycle/bicycle, and other). Response options included "yes" and "no". The total number of physical activity equipment available at home was generated by aggregating these items. Higher estimates represented having more physical activity equipment available in the home. Almost perfect and good one-week test-retest reliability were shown for the yard space (kappa $=0.96)$ and availability of physical activity equipment questions $(\mathrm{ICC}=$ 0.75), respectively [19].

Availability of electronic devices at home and the presence of electronic devices in the toddlers' bedroom were the variables assessed within the home environment construct of the SMCB. Availability of electronic devices at home included 7 items and the presence of electronic devices in the bedroom included 3 items primarily based on a previous study [47]. Availability of electronic devices was assessed by asking parents to report on the number of electronic devices they have in their house (i.e., TV, video/ DVD/Blu-ray payer, desktop computer, laptop, tablet computer, cell phone, and video game console). The total number of electronic devices available in the home was generated by aggregating available items. Higher estimates represented having more screen time devices available in the home. Presence of electronic devices in the bedroom were also assessed by asking parents to indicate if their child had TV/ portable DVD player, computer (e.g., learning laptop, laptop, netbook, iPad, and cellphone) and video game console in their bedroom with response options, "yes" or "no". A dichotomous variable was generated with " 1 " having $\geq$ one electronic device and "0" as having none in the bedroom. Good and almost perfect one-week test-retest reliability were shown for the availability of electronic equipment in the home ( $\mathrm{ICC}=0.88)$, and presence of electronic equipment in the bedroom questions (kappa $=0.95)$, respectively [19].

\section{Neighborhood environment}

Suitability of playgrounds (physical activity) and neighborhood safety (physical activity and screen time) were the variables assessed within the neighborhood environment construct of the SMCB. Suitability of playgrounds included 3 items and neighborhood safety included a single item adopted from a previous study [47]. Suitability of playgrounds was assessed by asking parents to report on the playgrounds in their local neighborhood (i.e., number of playgrounds, having suitable equipment, free from litter, graffiti, vandalism, and dog droppings) on a 5-point scale ranging from "strongly disagree" to "strongly agree". Higher estimates represented having more suitable playgrounds. Neighborhood safety was measured by asking parents to report on their perceived safety for their child and themselves to walk/cycle/play during daytime on a 4point scale ranging from "strongly disagree" to "strongly agree". Higher estimates represented having a safer neighborhood. Substantial and moderate one-week test-retest reliability were shown for the neighborhood safety (kappa $=0.63)$ and suitability of playgrounds $(\mathrm{ICC}=0.58)$ questions, respectively [19]. In addition, good internal consistency at two time points were shown for the suitability of playgrounds question $(\alpha=0.80-0.84)$ [19].

\section{Covariates}

Covariates included toddlers' age, sex, race/ethnicity, main type of childcare, and household income based on a previous study from the PREPS project [28]. Parents were asked to report on their toddlers' birthdate, sex (male or female), race/ ethnicity (i.e., Aboriginal/First Nation, African-Canadian, Arabic, Asian/Pacific Islander, European Canadian/Caucasian, Hispanic/Latino/Latina, or Other), hours per week spent in care other than parents (i.e., daycare center, home daycare, another adult in your home, another adult outside your home, other), and gross household income over the past 12 months (quartiles ranging from $<\$ 25,000$ to $>$ $\$ 100,000$, or 'do not know'). Consistent with previous studies involving the current sample [28, 48], toddlers' race/ethnicity was categorized into two groups (i.e., European-Canadian/ Caucasian and Non-European-Canadian/Non-Caucasian), 
household income was categorized into three groups (i.e., $\leq$ $\$ 50,000, \$ 50,001-\$ 100,000$, and $>\$ 100,000$ ), and the main type of childcare was categorized into four groups (i.e., parental care, childcare center, home daycare, and other).

\section{Statistical analysis}

The data were evaluated for normality, linearity, homoscedasticity, multicollinearity, and for potential outliners. Two toddlers and five parents with extremely high screen time values ( $\geq \pm 3$ standard deviations [SD]) were truncated below \pm 3 SD. In addition, 22 parents who exceeded $180 \mathrm{~min} /$ day of walking, MPA, or VPA variables were truncated to be equal to $180 \mathrm{~min} /$ day according to the IPAQ scoring protocol (www.ipaq.ki.se). All continuous variables were within an acceptable range of kurtosis and skewness $( \pm 2)$ [49-51], thus, no transformations were made. Means and standard deviations $(M \pm S D)$ for continuous variables and frequencies (\%) for categorical variables were calculated to describe participant characteristics. Spearman's rank correlations were performed to examine correlations between the SMCB variables. Statistical significance was set at $p<0.05$. To create the most parsimonious models, physical activity variables not significantly correlated with toddlers' physical activity and screen time variables not significantly correlated with toddlers' screen time were removed from the hypothesized model before the main analysis. The strength of a correlation coefficient was defined as weak if coefficients were below 0.3 , moderate if coefficients ranged from 0.3 to 0.5 , and strong if coefficients were greater than 0.5 [52].

To operationalize the SMCB [17] for structural equation modeling (SEM), an adapted version was developed in accordance with the previous literature pertaining to the correlates of physical activity and screen time among children in the early years $[12,20-23]$ and statistical principles of SEM [53] (see Fig. 1). The adapted model included three main changes from the original SMCB. First, the directionality of associations between constructs was specified. Second, a direct path between parental cognitions and children's behavior was added so the indirect effect of parental cognitions on children's behavior and the environment could be estimated [53]. Finally, the environment was separated into the home and neighborhood environment because the directionality of associations was thought to be different between these two environment settings [54-56].

Since a binary outcome was part of our hypothesized model (i.e., having versus not having electronics in the bedroom), the Markov Chain Monte Carlo algorithm (MCMC) methods were employed to obtain Bayesian estimation in SEM. Unlike frequentist analysis (e.g., maximum likelihood), Bayesian analysis provides parameter estimates from background knowledge (i.e., prior) to inform new data (i.e., likelihood), and MCMC sampling methods achieve these estimates from the mean of the posterior distribution [57, 58]. Therefore, Bayesian and frequentist methods differ in their definition of probability. With the frequentist approach, probability is determined based on one true regression coefficient that is fixed but unknown. However, in Bayesian theorem, probability is a degree of belief from our a priori knowledge that a relationship exists between variables. The likelihood of data is then used to weigh the prior, which yields the posterior distribution in Bayesian theorem [58]. The degree of beliefs in the Bayesian approach can be updated when we have further information (i.e., posterior distribution), while probabilities are estimated directly from samples with confidence intervals in the frequentist approach [58].

In this study, the relationships between variables are largely unknown, therefore we used uninformative (diffuse) prior. This method is thought to have minimum impact on the model estimates [59]. The hypothesized model (Fig. 1) was fitted after controlling for toddlers' age, sex, race/ethnicity, main childcare type, and household income. Standardized estimates (i.e., a single measure of the middle of the posterior distribution) and $95 \%$ credible intervals $(95 \% \mathrm{CI})$ for posterior estimates were reported. The Bayesian credible interval is interpreted as a probability statement about the parameter itself. For example, Prob $(a \leq \theta \leq b)=0.95)$ indicates that one is $95 \%$ sure that the true value of $\theta$ lies between $a$ and $b$ [58]. Stable parameter estimates were determined when the convergence statistic was less than 1.002 and when each Bayesian SE had a value lower than 0.05 [60]. Model fit was checked by computing Bayesian posterior predictive $p$ values. The model was determined as well-fitted when posterior predictive $p$ value was close to 0.50 [58]. In Bayesian inference, plausible reasoning, instead of frequentist's significant testing, is employed. Plausible reasoning attempts to validate or invalidate hypotheses using uncertain information and can be used to reason about the truth of single hypothesis $(\mathrm{H}$ or $\neg \mathrm{H})$ or choose from a number of competing hypotheses (H1) [61]. In this study, plausibility refers to the degree to which a statement can be believed and can be represented by likelihood or probability [61]. Specifically, a plausible association refers to the probability that a regression coefficient resides between the upper and lower limits of 95\% CIs. Prior to Bayesian SEM, latent variables were created for variables with multiple items. IBM SPSS Statistics 20 and IBM SPSS AMOS 20 (IBM Corp, NY) were used to perform the statistical analyses.

\section{Results}

A total of 203 out of the 257 participants had complete data on the key SMCB variables from the PREPS questionnaire. As for demographic variables, 12 participants did not respond or responded "do not know" to the household income question and one participant did not indicate race/ethnicity, leaving a total sample of 193 toddlers for the analyses involving screen time. Between the samples of included $(n=193)$ and excluded $(n=$ ranged 
from 44 to 64 due to missing cases), no significant differences were observed in toddlers' age (1.6 \pm 0.2 vs. $1.6 \pm 0.4)$, sex (boys: $49.2 \%$ vs. 47.8\%), race/ethnicity (Caucasian/ European-Canadian descent: $53.9 \%$ vs. $55.6 \%$ ), household income (15.5 vs. $27.5 \%$ in $\leq \$ 50,000 ; 38.3 \%$ vs. $37.3 \%$ in $\$ 50,000-\$ 100,000 ; 46.1 \%$ vs. $35.3 \%$ in $>\$ 100,000)$, or the main type of childcare $(35.8 \%$ vs. $23.1 \%$ in parental care; $18.7 \%$ vs. $15.4 \%$ in childcare center; $14.0 \%$ vs. $13.8 \%$ in home daycare; $31.6 \%$ vs. $47.7 \%$ in other).

A total of 123 out of the 193 participants provided complete accelerometry data and were included in the analyses involving physical activity. Between samples of included $(n=123)$ and excluded $(n=70)$ participants, no significant differences were observed in toddlers' age (1.6 \pm 0.2 vs. $1.6 \pm$ 0.3 ), sex (boys: $53.7 \%$ vs. $45.7 \%$ ), race/ethnicity (Caucasian/ European-Canadian descent: $58.5 \%$ vs. $45.7 \%)$, household income (12.2 vs. $21.4 \%$ in $\leq \$ 50,000 ; 39.8 \%$ vs. $35.7 \%$ in $\$ 50,000-\$ 100,000 ; 48.0 \%$ vs. $42.9 \%$ in $>\$ 100,000)$, or the main type of childcare $(36.6 \%$ vs. $34.3 \%$ in parental care; $18.7 \%$ vs. $18.6 \%$ in childcare center; $14.6 \%$ vs. $12.9 \%$ in home daycare; $30.1 \%$ vs. $34.3 \%$ in other). A detailed description of participant characteristics is presented in Table 1 . The average time spent in front of a screen was $101.8 \pm 108.8 \mathrm{~min} /$ day among toddlers. Toddlers spent an average of $298.0 \pm$ $39.9 \mathrm{~min} /$ day in TPA, with $58.7 \pm 18.7 \mathrm{~min}$ in MVPA.

Correlations between SMCB screen time variables are summarized in Table 2. Variables that were significantly negatively correlated with toddlers' screen time included parental limits on toddlers' screen time $(r=-0.407)$, barrier self-efficacy for limiting screen time $(r=-0.432)$, and neighborhood safety $(r=-0.310)$. Variables that were significantly positively correlated with toddlers' screen time included parental modeling of screen time $(r=0.302)$, negative outcome expectations for limiting screen time $(r=0.414)$, and having at least one electronic device in the bedroom $(r=0.312)$. The strength of these correlations was moderate. Three variables not significantly correlated with toddlers' screen time (i.e., activity temperament $[r=0.118]$, positive outcome expectations for limiting toddlers' screen time $[r=-0.073]$, and total number of electronic devices at home $[r=-0.061]$ ) were removed from the hypothesized model and excluded from further analysis. No significant correlations were observed between the SMCB physical activity variables and MVPA or TPA (Table 3) or between SMCB physical activity variables and LPA (data not shown). Therefore, SEM for the physical activity outcome was not performed.

Based on the results of the correlation analyses, the following variables were included in the SEM for screen time: negative outcome expectations and barrier self-efficacy of screen time limits, limits on screen time, parental modeling of screen time, presence of electronic equipment in bedroom, and neighborhood safety (Fig. 1). Two variables existed for parental cognitions (i.e., negative outcome expectations, barrier self-efficacy), and parental behavior (i.e., parental limits on toddlers' screen time, parental modeling of screen time) constructs. The SMCB hypothesized model met the assumptions for stable parameter estimates with a convergence statistic of $\leq 1.001$. Additionally, Bayesian standard errors for each parameter estimate was lower than 0.03. The SMCB hypothesized model was also shown to be well-fitted (Posterior predictive $p=0.48$ ) (see Appendix A).

The SMCB hypothesized screen time model is shown in Fig. 2. No plausible direct associations were observed between parental cognitions and toddlers' screen time. However, plausible indirect associations were observed between parental cognitions and toddlers' screen time, through parental behaviors. Specifically, higher negative outcome expectations for limiting toddlers' screen time was associated with lower parental limits on toddlers' screen time $(\beta=-0.147$, $95 \% \mathrm{CI}=-0.169,-0.125)$, and in turn, lower parental limits on toddlers' screen time was associated with higher screen time among toddlers $(\beta=-0.179,95 \% \mathrm{CI}=-0.309,-0.052)$ Similarly, higher barrier self-efficacy for limiting toddlers' screen time was associated with higher parental limits on toddlers' screen time $(\beta=0.451,95 \% \mathrm{CI}=0.315,0.572)$, and in turn, higher parental limits on toddlers' screen time was associated with lower screen time among toddlers $(\beta=-0.179,95 \% \mathrm{CI}=-0.309,-0.052)$.

Parental modeling did not mediate the relationship between parental cognitions and toddlers' screen time. However, higher parental modeling of screen time was directly associated with higher screen time among toddlers $(\beta=0.212,95 \% \mathrm{CI}=0.099,0.325)$. In addition, higher parental modeling of screen time was associated with having at least one electronic device in the bedroom $(\beta=0.146,95 \%$ $\mathrm{CI}=0.010,0.277$ ) and, in turn, having at least one electronic device in the bedroom, compared to having no electronic device in the bedroom, was associated with higher screen time among toddlers $(\beta=0.250$, 95\% $\mathrm{CI}=0.130,0.365)$. No plausible direct and indirect associations were observed between neighborhood safety and toddlers' screen time.

\section{Discussion}

To the authors' knowledge, this study was the first to use the SMCB to guide the comprehensive examination of the key correlates of physical activity and screen time in the early years age group. The interplay of important correlates associated with toddlers' screen time was identified. As hypothesized, and in line with the SMCB model, parental cognitions (negative outcome expectations, barrier self-efficacy for limiting screen time) and behaviors (parental limits on screen time, parental modeling of screen time), and the home environment (presence of electronic devices in the bedroom) were independently and simultaneously associated with toddlers' screen time. Specifically, parental cognitions were indirectly associated with toddlers' screen time through 
Table 1 Demographic and Socialization Model of Child Behaviorcharacteristics among toddlers and their parents

\begin{tabular}{|c|c|}
\hline & $n=193$ \\
\hline \multicolumn{2}{|l|}{ Demographic characteristics } \\
\hline Toddlers' age & $1.6 \pm 0.2$ \\
\hline \multicolumn{2}{|l|}{ Toddlers' sex } \\
\hline Boys & $50.8(98)$ \\
\hline Girls & $49.2(95)$ \\
\hline \multicolumn{2}{|l|}{ Toddlers' race/ethnicity } \\
\hline European-Canadian/Caucasian & $53.9(104)$ \\
\hline Other $^{a}$ & $46.1(89)$ \\
\hline \multicolumn{2}{|l|}{ Household income } \\
\hline$<\$ 50,000$ & $15.5(30)$ \\
\hline$\$ 50,001$ to $\$ 100,000$ & $38.3(74)$ \\
\hline$\geq \$ 100,000$ & $46.1(89)$ \\
\hline \multicolumn{2}{|l|}{ Main type of childcare } \\
\hline Parental & $35.8(69)$ \\
\hline Other $^{\text {b }}$ & $64.2(124)$ \\
\hline \multicolumn{2}{|l|}{ SMCB characteristics } \\
\hline Activity temperament $(0-7)$ & $5.5 \pm 0.8$ \\
\hline \multicolumn{2}{|l|}{ Screen time } \\
\hline TV (min/day) & $92.7 \pm 147.5$ \\
\hline VG (min/day) & $15.5 \pm 38.7$ \\
\hline Total screen time (TV + VG; min/day) & $101.8 \pm 108.8$ \\
\hline \multicolumn{2}{|l|}{ Physical activity $(n=123)$} \\
\hline LPA (min/day) & $239.1 \pm 27.5$ \\
\hline MVPA (min/day) & $58.7 \pm 18.7$ \\
\hline TPA (min/day) & $298.0 \pm 39.9$ \\
\hline \multicolumn{2}{|l|}{ Screen time: Parental behavior } \\
\hline \multicolumn{2}{|l|}{ Screen time modeling } \\
\hline TV (min/day) & $80.8 \pm 88.5$ \\
\hline Computer (min/day) & $77.4 \pm 107.6$ \\
\hline VG (min/day) & $1.8 \pm 7.8$ \\
\hline Total screen time (TV + Computer + VG; min/day) & $147.5 \pm 114.9$ \\
\hline Limit on toddlers' screen time $(0-7)$ & $2.8 \pm 2.5$ \\
\hline \multicolumn{2}{|l|}{ Screen time: Parental cognition } \\
\hline Positive outcome expectations (0-7) & $4.6 \pm 2.2$ \\
\hline Negative outcome expectations (0-7) & $2.5 \pm 1.6$ \\
\hline Barrier self-efficacy (0-7) & $4.6 \pm 1.9$ \\
\hline \multicolumn{2}{|l|}{ Physical activity: Parental behavior $(\mathrm{n}=123)$} \\
\hline \multicolumn{2}{|l|}{ Physical activity modeling } \\
\hline Total physical activity $\left(M E T \cdot\right.$ min week $^{-1}$ ) & $3198.8 \pm 2902.7$ \\
\hline Physical activity support (0-7) & $4.9 \pm 1.4$ \\
\hline \multicolumn{2}{|l|}{ Physical activity: Parental cognition $(n=123)$} \\
\hline Positive outcome expectations $(0-7)$ & $6.5 \pm 0.8$ \\
\hline Negative outcome expectations (0-7) & $4.1 \pm 1.6$ \\
\hline Barrier self-efficacy $(0-7)$ & $4.6 \pm 1.3$ \\
\hline \multicolumn{2}{|l|}{ Home environment } \\
\hline \multicolumn{2}{|l|}{ Screen time } \\
\hline Presence of at least one electronic equipment in be & $12.4(24)$ \\
\hline
\end{tabular}

Table 1 Demographic and Socialization Model of Child Behaviorcharacteristics among toddlers and their parents (Continued)

\begin{tabular}{ll}
\hline & $n=193$ \\
\hline Availability of electronic equipment (Total number) $^{\S}$ & $9.1 \pm 3.1$ \\
Physical activity $(n=145)$ & \\
Availability of PA equipment (total number) & d \\
Yard space (1-5) & $14.6 \pm 1.8$ \\
$\quad$ Suitability of playgrounds (1-5) & $3.5 \pm 1.0$ \\
Neighborhood environment & $3.9 \pm 0.8$ \\
Neighborhood safety (1-4) & $3.3 \pm 0.7$ \\
\hline
\end{tabular}

Data are presented as mean \pm standard deviation for continuous/ordinal variables and percentages $(\mathrm{n})$ for dichotomous variables

$\mathrm{SMCB}=$ Socialization Model of Child Behavior

${ }^{a}$ Non-European-Canadian/Non-Caucasian included aboriginal/First Nation, African-Canadian, Arabic, Asian/Pacific Islander, Hispanic/Latino/Latina, and others (self-expressed)

${ }^{b}$ Other included childcare center, home daycare, and another adult (e.g., friend, relative, nanny, baby sitter) in and outside home 'Electronic equipment included TV, video/DVD/Blu-ray player, desktop computer, laptop, tablet computer, cell phone, and video game console dPA equipment included balls, basketball hoop, bats/racquets/golf clubs, climbing equipment, gardening tools, play house, pool or beach toys,

tricycle/bicycle, and other (self-described)

parental screen time limits. Parental modeling of screen time was directly associated with toddlers' screen time and indirectly through having at least one device in the bedroom. However, neighborhood safety, which was significantly correlated with toddlers' screen time was not associated with toddlers' screen time in the SEM analysis. Additionally, no correlates of physical activity, in terms of TPA, LPA, or MVPA were identified.

The finding in the present study that parental cognitive factors were significantly correlated with toddlers' screen time is consistent with two previous studies [34, 62]. Specifically, higher parental self-efficacy to limit screen time was associated with lower screen time among Canadian children aged 0 to 5 years [34] and Australian children aged 1 to 5 years [62]. However, it is counterintuitive to hypothesize that parental cognitions will have a direct effect on children's behavior because cognitions are intrinsic to individuals and one's cognitions can only be directly translated into the behavior of their own and not to the behavior of others [63]. As Taylor and colleagues [17] stipulated in the SMCB model, the association between parental cognitions and children's behavior is likely due to one or more parental behavior variables that mediate the association. Through the use of SEM, the present study provided evidence for this indirect association. Specifically, negative outcome expectations and barrier self-efficacy for limiting screen time were not directly associated with toddlers' screen time; rather, they were indirectly associated with toddler' screen time through parental limits on toddler's screen time. Unlike negative outcome expectations and barrier self-efficacy, positive outcome expectations did not appear to be an important correlate of toddler's screen time. This may be explained by the fact that zero screen 
Table 2 Spearman rank correlations (one-tailed) between measures of the home and neighborhood environments, parental cognitions and modeling, and toddlers' temperament and screen time $(n=193)$

\begin{tabular}{|c|c|c|c|c|c|c|c|c|c|}
\hline & 1 & 2 & 3 & 4 & 5 & 6 & 7 & 8 & 9 \\
\hline \multicolumn{10}{|l|}{ Toddler Behavior } \\
\hline \multicolumn{10}{|l|}{ 1. Screen time } \\
\hline \multicolumn{10}{|c|}{ Toddler Cognition/Personal Attributes } \\
\hline 2. Temperament & .118 & & & & & & & & \\
\hline \multicolumn{10}{|c|}{ Parent Cognition/Behavior } \\
\hline 3. Screen time & $.302^{* *}$ & .072 & & & & & & & \\
\hline 4. Limit $^{\mathrm{a}}$ & $-.407^{* *}$ & $-.120^{*}$ & $-.198^{* *}$ & & & & & & \\
\hline 5. Positive $\mathrm{OE}^{\mathrm{a}}$ & -.073 & -.001 & -.045 & $.194^{* *}$ & & & & & \\
\hline 6. Negative $O E^{a}$ & $.414^{* *}$ & -.102 & $.145^{*}$ & $-.267^{* *}$ & .021 & & & & \\
\hline 7. Barrier $S E^{a}$ & $-.432^{* *}$ & .000 & $-.180^{* *}$ & $.454^{* *}$ & $.165^{*}$ & $-.431^{* *}$ & & & \\
\hline \multicolumn{10}{|l|}{ Home environment } \\
\hline 8. Bedroom ${ }^{b}$ & $.312^{* *}$ & $.152^{*}$ & $.134^{*}$ & -.039 & -.015 & $.155^{*}$ & $-.186^{* *}$ & & \\
\hline 9. Availability ${ }^{b}$ & -.061 & $-.083^{*}$ & .104 & .038 & $-.145^{*}$ & .035 & -.075 & .052 & \\
\hline \multicolumn{10}{|c|}{ Neighborhood environment } \\
\hline 10. Safety & $-.310^{* *}$ & -.006 & $-.140^{*}$ & .047 & $.120^{*}$ & $-.188^{* *}$ & $.176^{* *}$ & $-.262^{* *}$ & .069 \\
\hline
\end{tabular}

aLimit: Parental limit on screen time; OE Outcome expectations, SE Self-efficacy

${ }^{b}$ Bedroom: Presence of electronic equipment in bedroom; Availability: Total number of electronic equipment at home

${ }^{*} p<.05 ;{ }^{* *} p<.01$

time is often seen as unrealistic and impractical by parents $[64,65]$, and the negative outcomes of limiting screen time assessed in this study represented more practical day to day challenges (e.g., less time for parents to do other things, disruption of family practices and routines, unhappy child) than the potential positive outcomes assessed (e.g., improvements to child health, mood/behavior, social skills). Given the dearth of evidence in this area, future research is needed to confirm and build on these findings.

Parental cognitive factors were not associated with parental modeling of screen time; however, parental modeling of screen time was directly associated with toddlers' screen time. Combined, the findings from this study add to the growing evidence that parental behavior, including limits and modeling, is important in shaping screen time behavior

Table 3 Spearman rank correlations (one-tailed) between measures of the home and neighborhood environments, parental cognition and physical activity, and toddlers' temperament, and MVPA (non-shaded)\TPA (shaded) $(n=123)$

\begin{tabular}{|c|c|c|c|c|c|c|c|c|c|c|c|}
\hline & 1 & 2 & 3 & 4 & 5 & 6 & 7 & 8 & 9 & 10 & 11 \\
\hline \multicolumn{12}{|l|}{ Toddler Behavior } \\
\hline 1. MVPAITPA & & .036 & .040 & -.057 & -.088 & -.113 & -.097 & .006 & .043 & .042 & .060 \\
\hline \multicolumn{12}{|c|}{ Toddler Cognition/Personal Attributes } \\
\hline 2. Temperament & -.043 & & .052 & -.062 & .055 & -.019 & -.097 & .115 & -.084 & .009 & -.034 \\
\hline \multicolumn{12}{|c|}{ Parent Cognition/Behavior } \\
\hline 3. MET.min $\cdot$ week $^{-1}$ & .070 & .052 & & $.228^{* *}$ & .128 & -.047 & .110 & $-.162^{*}$ & .082 & -.004 & .055 \\
\hline 4. PA support & -.131 & -.062 & $.228^{* *}$ & & $.351^{* * *}$ & -.065 & $.355^{* * *}$ & $-.248^{* *}$ & $.290^{* *}$ & $.201^{*}$ & $.211^{*}$ \\
\hline 5. Positive $\mathrm{OE}^{\mathrm{a}}$ & -.050 & .055 & .128 & $.351^{* * *}$ & & .111 & $.333^{* * *}$ & $-.179^{*}$ & $.173^{*}$ & .080 & .110 \\
\hline 6. Negative $O E^{a}$ & -.065 & -.019 & -.047 & -.065 & .111 & & .074 & -.020 & -.142 & $-.198^{*}$ & $-.199^{*}$ \\
\hline 7. Barrier SE & -.130 & -.097 & .110 & $.355^{* * *}$ & $.333^{* * *}$ & .074 & & $-.265^{* *}$ & .026 & $.172^{*}$ & .088 \\
\hline \multicolumn{12}{|l|}{ Home environment } \\
\hline 8. Availability ${ }^{b}$ & .017 & .115 & $-.162^{*}$ & $-.248^{* *}$ & $-.179^{*}$ & -.020 & $-.265^{* *}$ & & $-.250^{* *}$ & -.081 & -.053 \\
\hline 9. Yard Space & -.004 & -.084 & .082 & $.290^{* *}$ & $.173^{*}$ & -.142 & .026 & $-.250^{* *}$ & & $.183^{*}$ & $.171^{*}$ \\
\hline \multicolumn{12}{|c|}{ Neighborhood environment } \\
\hline 10. Suitability ${ }^{b}$ & .068 & .009 & -.004 & $.201^{*}$ & .080 & $-.198^{*}$ & $.172^{*}$ & -.081 & $.183^{*}$ & & $.380^{* * *}$ \\
\hline 11. Safety ${ }^{\ddagger}$ & -.036 & -.034 & .055 & $.211^{*}$ & .110 & $-.199^{*}$ & .088 & -.053 & $.171^{*}$ & $.380^{* * *}$ & \\
\hline
\end{tabular}




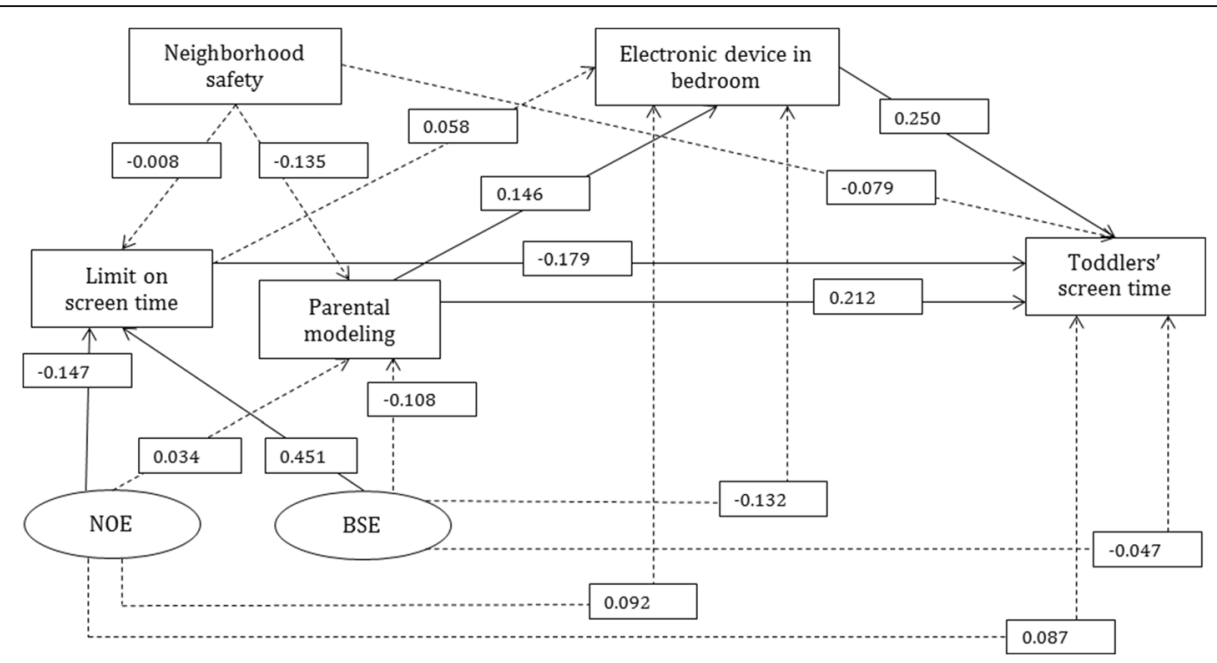

Fig. 2 The SMCB hypothesized screen time model $(n=193)$. Note: All solid line parameters are within 95\% credible intervals; dashed line parameters are not within 95\% credible intervals. Ovals represent latent constructs and rectangles represent measured variables. Only standardized beta coefficients are presented and the error terms, covariates, 95\% credible intervals and measurements are not presented for clarity. Analysis was adjusted for toddler's age, sex, race/ethnicity, main childcare type and household income. NOE: Negative outcome expectations; BSE: Barrier self-efficacy

during early childhood [12, 22]. Though not examined in this study, parental limits and role modeling with respect to screen time may also interact with one another, and simultaneously influence toddlers' screen time. For instance, De Decker and colleagues [66] found that parental rules about TV viewing time mediate the relationship between parents' and preschoolers' TV viewing time in Australian and Belgian samples. Also, in line with the SMCB model [17], findings of the present study suggest that parental screen time modeling is not only directly associated with toddlers' screen time but also indirectly through the home environment. This finding builds upon previous literature $[12,21,66-69]$ that has only considered the direct effect between parental modeling and toddler's screen time behavior. It is possible that parents who spend longer hours in front of a screen may create the home environment that is conducive to screen time for their toddlers. Therefore, creating healthy home environments may not only have implications for toddlers but for the whole family unit.

The roles electronic devices play in young families' lives are an important area of future inquiry to inform the creation of healthy home environments. Findings suggest the location of the electronic devices (i.e., bedroom) is a more important correlate of toddlers' screen time than the total number of devices in the home. Interestingly, having an electronic device in the bedroom is a consistent correlate of screen time across early years and school-aged groups [69-73]. Therefore, creating healthy home environments with screen-free bedrooms from an early age may positively impact screen time throughout childhood. Common reasons for having a TV in the bedroom of a child in the early years, including helping children fall asleep, keeping children occupied, and rewarding children for good behavior [74], should be taken into consideration when encouraging families to create healthy home environments. In addition, given the portability of electronic devices (e.g., tablets, laptops, cellphones) in today's homes, placing parameters on where devices are permitted in the home should also be considered in future efforts to minimize screen exposure among toddlers.

In contrast to the home environment, the neighborhood environment was not associated with toddlers' screen time in the SEM analysis. Unlike the home environment, parents do not have direct control over the environment of their neighborhood apart from the potential selection of what neighborhood to live in. Thus, neighborhood safety was included as an exogenous variable in which its value is not dependent on other variables in the model. More empirical evidence exists with older children and adolescents that neighborhood safety is associated with behaviors including screen time [20, 42, 75-77]. Conversely, only one study showed the association between neighborhood safety and screen time among 3 -year-olds [78], and no corresponding evidence is available in toddlers. While evidence is lacking, it is possible that the immediate environment (i.e., home) is more important for younger children, whereas the distal environment (i.e., neighborhood) is more important for older age groups $[16,75,79]$. For instance, in the present study while a moderate negative correlation was observed between neighborhood safety and toddlers' screen time, no association was observed when neighborhood safety was fitted in the SMCB hypothesized model 
with other important parental and home environment correlates. This suggests that the relative predictive importance of neighborhood safety is not as important as other independent variables included in the model simultaneously [54]. Further research is needed to identify at what age the neighborhood environment becomes increasingly important for screen time.

This study was the first to demonstrate the dynamic and complex roles of parental cognitions, parental behaviors, and the home environment in determining toddlers' screen time patterns. Findings can help to inform targets for future interventions aiming to establish healthy screen time behaviors among toddlers. For example, identifying types of support that parents need in limiting toddler's screen time, and subsequently providing appropriate, feasible, and sustainable resources and strategies is warranted. Also, providing opportunities to cultivate confidence in encouraging alternative behaviors (e.g., reading books, dancing around, playing indoor games) may increase parental barrier selfefficacy and decrease negative outcome expectations for limiting toddlers' screen time. Given that maternal selfefficacy for limiting TV viewing has shown to track over time [80], targeting parents early before the onset of children's screen time exposure may be of importance. Similarly, early intervention in regard to the home environment also appears important, given that parents with higher screen time were more likely to have a toddler who had an electronic device in their bedroom, an important predictor of screen time in younger and older children $[69,72]$. In addition, interventions targeting parental behavioral change should be specific to the parental behavior that the intervention is trying to modify. For example, parental screen time limiting practices should be targeted along with changing parental cognitions; whereas, parental modeling should be targeted along with changing the home environment. It is also important to note that interventions to minimize toddlers' screen time may need to target both parents' and toddlers' screen time to yield successful outcomes. However, mothers were the primary participants in this study (87.6\%). Qualitative evidence suggests that limiting screen time is challenging for a new parent when their spouse likes watching TV or playing video games [81]. Therefore, future research is required to confirm these findings in other main caregivers in the home (i.e., father, spouse, or common-law partner) to inform family-based interventions that include the entire family unit where applicable.

In contrast to toddlers' screen time, findings of the present study with regard to toddlers' physical activity were not supported by the SMCB model. It is possible that other important correlates of toddlers' physical activity may have been missed. Previous studies examining individual correlates of physical activity in the toddler age group have observed some significant associations with correlates not examined in the present study. For example, more maternal-child interactions [82] and lower parental hostility were found to be associated with higher physical activity among toddlers. In contrast to the findings of the present study, higher levels of paternal [83] or maternal physical activity [84, 85], and higher perceived safety of outdoor play environments [55] have also been found to be associated with higher physical activity among toddlers in previous studies. It is difficult to determine the most important correlates associated with toddlers' physical activity at this time because of the dearth of empirically based knowledge in this age group. Further research is needed to confirm our findings as well as explore whether other correlates not examined in this study or understudied in previous literature (e.g., co-participation, built environment, child care environment) are of importance, and whether other theoretical models are better suited to guide the examination of correlates of toddlers' physical activity.

The major strengths of this study are the relatively large sample of toddlers and the objective measure of physical activity. The use of structural equation modeling with the application of Bayes' theorem, which allowed us to simultaneously evaluate the associations among multiple important variables assessed via the hypothesized model is another strength. Furthermore, these methods are known to improve estimation accuracy in complex statistical models such as structural equation modeling under cases of small sample sizes. In addition, Bayesian methods using MCMC allow structural equation models to have binary outcome variables. Other study strengths include the theoretical underpinning and the demographically and socioeconomically diverse sample. Lastly, this study included behavior-specific correlates for physical activity and screen time within the same sample.

A limitation of this study is the use of proxy-reported data except for toddlers' physical activity; thus, our findings are subject to information bias (e.g., recall and social desirability). Nonetheless, psychometric properties of the PREPS questionnaire are previously established [19]. The crosssectional design is a further limitation of this study. However, our hypotheses and analyses were guided by a theory and developed based upon temporal directionality and model specification [86]. Only $64 \%$ of the analytic sample had accelerometry data; thus, the physical activity specific analyses included significantly fewer toddlers compared to the screen time specific analyses. However, no demographic differences were observed between included and excluded samples. In addition, some studies have suggested that the correlates of physical activity and screen time may differ by sex [87], ethnicity [88], and socioeconomic status [89] as early as the preschool years. Though we were not able to test sociodemographic-stratified models, sociodemographic correlates of physical activity and screen time identified in a previous study involving the same sample [28] were controlled in the SEM analysis. 


\section{Conclusions}

Parents appear to play a critical role in establishing healthy screen time behaviors among their toddlers by practicing screen time limits, role modeling healthy screen time behaviors themselves, and creating screen-free bedrooms within the home environment. However, important correlates of physical activity in toddlers are currently unclear. Further investigation is required to build on our findings with regard to the potential role of parental and environmental characteristics in toddlers' screen time using longitudinal and experimental study designs to confirm causality. Given that toddlerhood is a window of opportunity for establishing healthy behavioral patterns at home, and that the design of our hypothesized model is guided by the SMCB model, our results can help inform future familybased interventions targeting screen time among toddlers.

\section{Appendix}

Table 4

\begin{tabular}{|c|c|c|c|c|}
\hline & $\begin{array}{l}\text { Standardized } \\
\text { direct effect }\end{array}$ & $\begin{array}{l}\text { Standard } \\
\text { deviations }\end{array}$ & $\begin{array}{l}95 \% \text { Credible } \\
\text { Intervals }\end{array}$ & Convergence \\
\hline \multicolumn{5}{|l|}{ Figure 2} \\
\hline \multicolumn{5}{|l|}{$\begin{array}{l}\text { Posterior predictive } \\
p=0.48\end{array}$} \\
\hline $\begin{array}{l}\text { Neighborhood safety } \\
\text { - > Parental limits }\end{array}$ & -0.008 & 0.067 & $-0.138,0.125$ & 1.001 \\
\hline $\begin{array}{l}\text { Neighborhood safety } \\
\text {-> Parental modeling }\end{array}$ & -0.135 & 0.073 & $-0.279,0.012$ & 1.001 \\
\hline $\begin{array}{l}\text { Neighborhood safety } \\
\text { - > Toddler's screen time }\end{array}$ & -0.079 & 0.061 & $-0.199,0.042$ & 1.001 \\
\hline $\begin{array}{l}\text { Negative outcome } \\
\text { expectations } \\
\text {-> Parental modeling }\end{array}$ & 0.034 & 0.081 & $-0.127,0.212$ & 1.000 \\
\hline $\begin{array}{l}\text { Negative outcome } \\
\text { expectations } \\
\text { - > Parental limits }\end{array}$ & -0.147 & 0.070 & $-0.169,-0.125$ & 1.000 \\
\hline $\begin{array}{l}\text { Negative outcome } \\
\text { expectations } \\
\text {-> Electronics in bedroom }\end{array}$ & 0.092 & 0.078 & $-0.058,0.248$ & 1.001 \\
\hline $\begin{array}{l}\text { Negative outcome } \\
\text { expectations } \\
\text {-> Toddler's screen time }\end{array}$ & 0.087 & 0.066 & $-0.043,0.217$ & 1.001 \\
\hline $\begin{array}{l}\text { Barrier self-efficacy } \\
\text { - > Parental limits }\end{array}$ & 0.451 & 0.065 & $0.315,0.572$ & 1.001 \\
\hline $\begin{array}{l}\text { Barrier self-efficacy } \\
\text { - > Parental modeling }\end{array}$ & -0.108 & 0.080 & $-0.269,0.052$ & 1.000 \\
\hline $\begin{array}{l}\text { Barrier self-efficacy } \\
->\text { Electronics in bedroom }\end{array}$ & -0.132 & 0.082 & $-0.292,0.029$ & 1.001 \\
\hline $\begin{array}{l}\text { Barrier self-efficacy } \\
\text { - > Toddler's screen time }\end{array}$ & -0.047 & 0.073 & $-0.187,0.097$ & 1.001 \\
\hline $\begin{array}{l}\text { Parental limits } \\
\text {-> Electronics in bedroom }\end{array}$ & 0.058 & 0.069 & $-0.095,0.211$ & 1.001 \\
\hline $\begin{array}{l}\text { Parental limits } \\
\text { - > Toddler's screen time }\end{array}$ & -0.179 & 0.066 & $-0.309,-0.052$ & 1.000 \\
\hline $\begin{array}{l}\text { Parental modeling } \\
->\text { Electronics in bedroom }\end{array}$ & 0.146 & 0.068 & $0.010,0.277$ & 1.000 \\
\hline $\begin{array}{l}\text { Parental modeling } \\
\text { - > Toddler's screen time }\end{array}$ & 0.212 & 0.058 & $0.099,0.325$ & 1.001 \\
\hline $\begin{array}{l}\text { Electronics in bedroom } \\
\text { - > Toddler's screen time }\end{array}$ & 0.250 & 0.059 & $0.130,0.365$ & 1.001 \\
\hline
\end{tabular}

\section{Abbreviations}

Cl: credible interval; ICC: intraclass correlation; LPA: light-intensity physical activity; M: mean; MCMC: Markov Chain Monte Carlo; MET: metabolic equivalent of tasks; MVPA: moderate- to vigorous-intensity physical activity; PREPS: Parents' Role in Establishing healthy Physical activity and Sedentary behavior habits; SD: standard deviation; SEM: structural equation modeling; SMCB: Socialization Model of Child Behavior; TPA: total physical activity;

TV: television; VG: video game

\section{Acknowledgements}

The authors are grateful to all the toddlers and parents who took part in this study. The authors would like to thank Alberta Health Services for facilitating recruitment, and Dorah Conteh for her help with project coordination and data collection. The authors would also like to thank Nicholas Kuzik and Stephen Hunter for their help with data collection and Helena Lee for her help with data entry.

\section{Funding}

This research was funded by the Canadian Institutes of Health Research (CIHR), the Institute of Human, Development, Child and Youth Health $(\mathrm{IHDCYH})$; and the Heart and Stroke Foundation (Alberta). VC is supported by a CIHR New Investigator Salary Award. KDH is supported by an Australian Research Council Future Fellowship (FT130100637) and an Honorary National Heart Foundation of Australia Future Leader Fellowship (100370). The funding bodies had no role in the design of the study; in the collection, analysis, and interpretation of data; or in writing the manuscript.

\section{Availability of data and materials}

The data set for the current study is available from the corresponding author upon reasonable request.

\section{Authors' contributions}

EL analyzed the data, and led the interpretation of the results as well as the writing of the paper. VC conceived and designed the study, secured funding, oversaw the study's conduct, conducted the data reduction of accelerometry data, and assisted with the interpretation of results and writing of the paper. All authors critically revised the paper for important intellectual content, and read and approved the final manuscript.

\section{Ethics approval and consent to participate}

Ethics approval was obtained from the University of Alberta Human Research Ethics Board, and all participating parents provided written informed consent.

\section{Consent for publication}

Not applicable.

\section{Competing interests}

The authors declare that they have no competing interests.

\section{Publisher's Note}

Springer Nature remains neutral with regard to jurisdictional claims in published maps and institutional affiliations.

\section{Author details \\ ${ }^{1}$ Faculty of Kinesiology, Sport, and Recreation, University of Alberta, Edmonton, AB T6G 2H9, Canada. Institute for Physical Activity and Nutrition, School of Exercise and Nutrition Sciences, Faculty of Health, Deakin University, Geelong, VIC 3220, Australia. ${ }^{3}$ School of Exercise Science, Physical and Health Education, University of Victoria, Victoria, BC V8W 2Y2, Canada. ${ }^{4}$ Department of Educational Psychology, Faculty of Education, University of Alberta, Edmonton, AB T6G 2G5, Canada.}

Received: 20 November 2017 Accepted: 26 January 2018

Published online: 09 February 2018

\section{References}

1. Carson V, Lee EY, Hewitt L, Jennings C, Hunter S, et al. Systematic review of the relationships between physical activity and health indicators in the early years (aged 0 to 4 years). BMC Public Health. 2017;17(S5):854. 
2. Kuzik N, Poitras VJ, Tremblay MS, Lee EY, Hunter S, Carson V. Systematic review of the relationships between the combinations of movement behaviors and health indicators in the early years (age 0 to 4 years). BMC Public Health. 2017;17(S5):849.

3. Poitras VJ, Gray CE, Janssen X, Aubert S, Carson V, Faulkner G, et al. Systematic review of the relationships between sedentary behavior and health indicators in the early years (aged 0-4 years). BMC Public Health. 2017;17(S5):868.

4. Carson V, Hunter S, Kuzik N, Gray CE, Poitras VJ, Chaput J-P, et al. Systematic review of sedentary behaviour and health indicators in school-aged children and youth: an update 1. Appl Physiol Nutr Metab. 2016;41:S240-65.

5. Poitras VJ, Gray CE, Borghese MM, Carson V, Chaput J-P, Janssen I, et al. Systematic review of the relationships between objectively measured physical activity and health indicators in school-aged children and youth 1. Appl Physiol Nutr Metab. 2016;41:S197-239.

6. Jones RA, Hinkley T, Okely AD, Salmon J. Tracking physical activity and sedentary behavior in childhood: a systematic review. Am J Prev Med. 2013; 44:651-8.

7. Janz KF, Burns TL, Levy SM. Tracking of activity and sedentary behaviors in childhood: the lowa bone development study. Am J Prev Med. 2005;29: 171-8.

8. Chaput J-P, Colley RC, Janssen I, Carson V, Roberts KC, Aubert S, et al. Proportion of preschool-aged children meeting the Canadian 24-hour movement guidelines for the early years and associations with adiposity: results from the Canadian health measures survey. BMC Public Health. 2017; 17(S5):829.

9. Tremblay MS, Carson V, Chaput J-P, Adamo KB, Aubert S, Choquette L, et al. Canadian 24-hour movement guidelines for the early years: an integration of physical activity, sedentary behaviour, and sleep. BMC Public Health. 2017;17(S5):874

10. Rhodes RE, Spence JC, Berry T, Deshpande S, Faulkner G, Latimer-Cheung $A E$, et al. Understanding action control of parental support behavior for child physical activity. Health Psychol. 2016;35(2):131-40.

11. Stearns JA, Rhodes R, Ball GD, Boule N, Veugelers PJ, Cutumisu N, Spence JC. A cross-sectional study of the relationship between parents' and children's physical activity. BMC Public Health. 2016;16:1129.

12. $\mathrm{Xu} \mathrm{H}$, Wen LM, Rissel C. Associations of parental influences with physical activity and screen time among young children: a systematic review. J Obes. 2015. https://doi.org/10.1155/2015/546925.

13. Rhee K. Childhood overweight and the relationship between parent behaviors, parenting style, and family functioning. Ann Am Acad Pol Soc Sci. 2008;615:11-37.

14. Carson V, Spence JC, Cutumisu N, Cargill L. Association between neighborhood socioeconomic status and screen time among pre-school children: a cross-sectional study. BMC Public Health. 2010;10:367.

15. Salmon J, Spence J, Timperio A, Cutumiso N. Living environments. In: Smith AL, SJH B, editors. Youth physical activity and sedentary behavior: challenges and solutions. Champaign: Human Kinextics; 2008. p. 403-28.

16. Bronfenbrenner U. The ecology of human development. Boston: Harvard university press; 2009.

17. Taylor WC, Baranowski T, Sallis JF. Family determinants of childhood physical activity: a social-cognitive model. In: Dishman RK, editor. Advances in exercise adherence. Champaign: Human Kinetics; 1994. p. 319-42.

18. Welk GJ. The youth physical activity promotion model: a conceptual bridge between theory and practice. Quest. 1999;51(1):5-23.

19. Carson VR, Rhodes RE, Rinaldi C, Rodgers W, Spence JC, Hesketh KD. Psychometric properties of a parental questionnaire for assessing correlates of toddlers' physical activity and sedentary behaviour. Measur Phys Educ Exerc Sci. 2017. https://doi.org/10.1080/1091367X.1092017.1322087.

20. Christian H, Zubrick SR, Foster S, Giles-Corti B, Bull F, Wood L, et al. The influence of the neighborhood physical environment on early child health and development: a review and call for research. Health Place. 2015;33:2536.

21. De Craemer M, De Decker E, De Bourdeaudhuij I, Vereecken C, Deforche B, Manios $Y$, et al. Correlates of energy balance-related behaviours in preschool children: a systematic review. Obes Rev. 2012;13(Suppl 1):13-28.

22. Duch $\mathrm{H}$, Fisher EM, Ensari I, Harrington A. Screen time use in children under 3 years old: a systematic review of correlates. Int J Behav Nutr Phys Act. 2013;10:102.

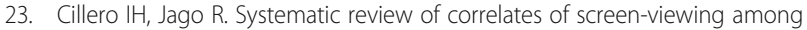
young children. Prev Med. 2010;51:3-10.
24. Hnatiuk J, Ridgers ND, Salmon J, Campbell K, McCallum Z, Hesketh K. Physical activity levels and patterns of 19-month-old children. Med Sci Sports Exerc. 2012;44:1715-20.

25. Trost SG, Fees BS, Haar SJ, Murray AD, Crowe LK. Identification and validity of accelerometer cut-points for toddlers. Obesity. 2012;20:2317-9.

26. Verbestel V, De Coen V, Van Winckel M, Huybrechts I, Maes L, De Bourdeaudhuij I. Prevention of overweight in children younger than 2 years old: a pilot cluster-randomized controlled trial. Public Health Nutr. 2014;17: 1384-92.

27. Wijtzes Al, Kooijman MN, Kiefte-de Jong JC, de Vries SI, Henrichs J, et al. Correlates of physical activity in 2-year-old toddlers: the generation $\mathrm{R}$ study. J Pediatr. 2013;163:791-9.

28. Carson V, Kuzik N. Demographic correlates of screen time and objectively measured sedentary time and physical activity among toddlers: a crosssectional study. BMC Public Health. 2017;17:187.

29. Hinkley T, O'connell E, Okely AD, Crawford D, Hesketh K, Salmon J. Assessing volume of accelerometry data for reliability in preschool children. Med Sci Sports Exerc. 2012;44:2436-41.

30. Pate RR, Almeida MJ, Mclver KL, Pfeiffer KA, Dowda M. Validation and calibration of an accelerometer in preschool children. Obesity. 2006;14:20006.

31. Willett W, Stampfer MJ. Total energy intake: implications for epidemiologic analyses. Am J Epidemiol. 1986;124:17-27.

32. Costa S, Barber SE, Cameron N, Clemes SA. Calibration and validation of the ActiGraph GT3X+ in 2-3 year olds. J Sci Med Sport. 2014;17:617-22.

33. Van Cauwenberghe E, Gubbels J, De Bourdeaudhuij I, Cardon G. Feasibility and validity of accelerometer measurements to assess physical activity in toddlers. Int J Behav Nutr PhyAct. 2011;8:67.

34. Carson V, Janssen I. Associations between factors within the home setting and screen time among children aged $0-5$ years: a cross-sectional study. BMC Public Health. 2012;12:539.

35. Carson V, Tremblay MS, Spence JC, Timmons BW, Janssen I. The Canadian sedentary behaviour guidelines for the early years (zero to four years of age) and screen time among children from Kingston, Ontario. Paediatr Child Health. 2013;18:25-8.

36. Colley RC, Garriguet D, Adamo KB, Carson V, Janssen I, Timmons BW, et al. Physical activity and sedentary behavior during the early years in Canada: a cross-sectional study. Int J Behav Nutr Phys Act. 2013;10:54.

37. Putnam SP, Jacobs J, Garstein M, Rothbart M. Development and assessment of short and very short forms of the early childhood behavior questionnaire (abstract). Baltimore: International Confeence on Infant Studies; 2010. https://research.bowdoin.edu/rothbart-temperament-questionnaires/files/ 2016/09/ICIS_2010_ECBQ_sf_poster.pdf. Accessed 4 Aug 2017

38. Anderson SE, Bandini L, Dietz W, Must A. Relationship between temperament, nonresting energy expenditure, body composition, and physical activity in girls. Int J Obes. 2004;28:300-6.

39. Bandura A. Self-efficacy: the exercise of control. New York: W. H. Freeman; 1997.

40. Bandura A. Reflections on self-efficacy. Adv Behav Res Ther. 1978;1:237-69.

41. McMinn AM, van Sluijs EM, Harvey NC, Cooper C, Inskip HM, Godfrey KM, et al. Validation of a maternal questionnaire on correlates of physical activity in preschool children. Int J Behav Nutr Phy Act. 2009;6:81.

42. Carson V, Janssen I. Neighborhood disorder and screen time among 10-16 year old Canadian youth: a cross-sectional study. Int J Behav Nutr PhyAct. 2012:9:66.

43. O'Conner TM, Chen TA, Del Rio RB, Baranowski T. Parent's outcome expectations of children's TV viewing, parent TV resitriction, and children's screen media use (Abstact). Ghent: International Society for Behavioural Nutrition and Physical Activity (ISBNPA) Annual Meeting; 2013. p. 534-5.

44. Craig $C L$, Marshall $A L$, Sjöström M, Bauman AE, Booth ML, Ainsworth BE, et al. International physical activity questionnaire: 12-country reliability and validity. Med Sci Sports Exerc. 2003;35:1381-95.

45. Sallis JF, Taylor WC, Dowda M, Freedson PS, Pate RR. Correlates of vigorous physical activity for children in grades 1 through 12: comparing parentreported and objectively measured physical activity. Pediatr Exerc Sci. 2002; 14:30-44.

46. Vaughn A, Hales D, Ward DS. Measuring the physical activity practices used by parents of preschool children. Med Sci Sports Exerc. 2013:45:2369-77.

47. Hinkley T, Salmon J, Okely AD, Crawford D, Hesketh K. The HAPPY study: development and reliability of a parent survey to assess correlates of preschool children's physical activity. J Sci Med Sport. 2012;15:407-17. 
48. Lee EY, Hesketh KR, Hunter S, Kuzik N, Rhodes RE, Rinaldi CM, et al. Meeting new Canadian 24-hour movement behaviour guidelines for the early years and associations with adiposity among toddlers living in Edmonton, Canada. BMC Public Health. 2017;17(S5):840.

49. Trochim WM, Donnelly JP. The research methods knowledge base. Cincinnati: Atomic Dog; 2001.

50. Field A. Discovering statistics using SPSS. London: Sage Publications; 2009.

51. Gravetter F, Wallnau L. Essentials of statistics for the behavioral sciences. 8th ed. Belmont: Wadsworth; 2014

52. Cohen J. A power primer. Psychol Bull. 1992;112:155-9.

53. Kline RB. Principles and practice of structural equation modelling. New York: Guilford Press; 2005.

54. Hinkley T, Salmon J, Okely AD, Hesketh K, Crawford D. Correlates of preschool children's physical activity. Am J Prev Med. 2012;43:159-67.

55. $\mathrm{Xu} \mathrm{H}$, Wen LM, Rissel C. Associations of maternal influences with outdoor play and screen time of two-year-olds: findings from the healthy beginnings trial. J Paediatr Child Health. 2014;50:680-6.

56. Chandra M, Jalaludin B, Woolfenden S, Descallar J, Nicholls L, Dissanayake C, et al. Screen time of infants in Sydney, Australia: a birth cohort study. BMJ Open. 2016;6:e012342.

57. Lee S-Y, Song $X-Y$. Evaluation of the Bayesian and maximum likelihood approaches in analyzing structural equation models with small sample sizes. Multivariate Behav Res. 2004:39:653-86.

58. van de Schoot R, Depaoli S. Bayesian analyses: where to start and what to report. Eur Health Psychol. 2014;16:75-84.

59. Depaoli S, Rus HM, Clifton JP, van de Schoot R, Tiemensma J. An introduction to Bayesian statistics in health psychology. Health Psychol Rev. 2017;11:248-64

60. Arbuckle J. IBM SPSS AMOS 22 User's Guide. Crawfordville: Amos Development Corporation; 2013.

61. Jaynes ET. Probability theory: the logic of science. London: Cambridge university press; 2003.

62. Campbell K, Hesketh K, Silverii A, Abbott G. Maternal self-efficacy regarding children's eating and sedentary behaviours in the early years: associations with children's food intake and sedentary behaviours. Pediatr Obes. 2010:5:501-8.

63. Conner M, Norman P. Predicting health behaviour. Birkshire: McGraw-Hill Education; 2005.

64. Brown A, Smolenaers E. Parents' interpretations of screen time recommendations for children younger than 2 years. J Fam Issues. 2016 doi:0192513X16646595

65. Evans CA, Jordan AB, Horner J. Only two hours? A qualitative study of the challenges parents perceive in restricting child television time. J Fam Issues. 2011;32:1223-44.

66. De Decker E, Hesketh K, De Craemer M, Hinkley T, De Bourdeaudhuij I, Salmon J, et al. Parental influences on preschoolers' TV viewing time: mediation analyses on Australian and Belgian data. J Phys Act Health. 2015;12:1272-9.

67. Mitchell J, Skouteris H, McCabe M, Ricciardelli LA, Milgrom J, Baur LA, et al. Physical activity in young children: a systematic review of parental influences. Early Child Dev Care. 2012;182:1411-37.

68. Maitland C, Stratton G, Foster S, Braham R, Rosenberg M. The dynamic family home: a qualitative exploration of physical environmental influences on children's sedentary behaviour and physical activity within the home space. Int J Behav Nutr Phys Act. 2014;11:157.

69. Veldhuis L, van Grieken A, Renders CM, HiraSing RA, Raat H. Parenting style, the home environment, and screen time of 5-year-old children: the 'be active, eat right'study. PloS Olne. 2014;9:e88486.

70. Tucker P, van Zandvoort MM, Burke SM, Irwin JD. The influence of parents and the home environment on preschoolers' physical activity behaviours: a qualitative investigation of childcare providers' perspectives. BMC Public Health. 2011;11:168.

71. De Jong E, Visscher T, HiraSing R, Heymans M, Seidell J, Renders C. Association between TV viewing, computer use and overweight, determinants and competing activities of screen time in 4-to 13-year-old children. Int J Obes. 2013;37:47-53.

72. Dennison BA, Erb TA, Jenkins PL. Television viewing and television in bedroom associated with overweight risk among low-income preschool children. Pediatrics. 2002;109:1028-35.

73. Van Zutphen M, Bell AC, Kremer PJ, Swinburn BA. Association between the family environment and television viewing in Australian children. J Paediatr Child Health. 2007;43:458-63.
74. Vandewater EA, Rideout VJ, Wartella EA, Huang X, Lee JH, Shim MS. Digital childhood: electronic media and technology use among infants, toddlers, and preschoolers. Pediatrics. 2007;119:e1006-15.

75. Carson V, Kuhle S, Spence JC, Veugelers PJ. Parents' perception of neighbourhood environment as a determinant of screen time, physical activity and active transport. Can J Public Health. 2010;101:124-7.

76. Davison KK, Lawson CT. Do attributes in the physical environment influence children's physical activity? A review of the literature. Int J Behav Nutr Phys Act. 2006:3:19.

77. Lee H, Tamminen KA, Clark AM, Slater L, Spence JC, Holt NL. A meta-study of qualitative research examining determinants of children's independent active free play. Int J Behav Nutr Phys Act. 2015;12:5.

78. Burdette HL, Whitaker RC. A national study of neighborhood safety, outdoor play, television viewing, and obesity in preschool children. Pediatrics. 2005; 116(3):657-62.

79. Holt NL, Spence JC, Sehn ZL, Cutumisu N. Neighborhood and developmental differences in children's perceptions of opportunities for play and physical activity. Health Place. 2008;14(1):2-14.

80. Hnatiuk JA, Salmon J, Campbell KJ, Ridgers ND, Hesketh KD. Tracking of maternal self-efficacy for limiting young children's television viewing and associations with children's television viewing time: a longitudinal analysis over 15-months. BMC Public Health. 2015:15:517.

81. Hesketh KD, Hinkley T, Campbell KJ. Children's physical activity and screen time: qualitative comparison of views of parents of infants and preschool children. Int J Behav Nutr Phys Act. 2012;9:152.

82. Hager E, Tilton N, Wang Y, Kapur N, Arbaiza R, Merry B, et al. The home environment and toddler physical activity: an ecological momentary assessment study. Pediatr Obes. 2017;12:1-9.

83. Walsh AD, Crawford D, Cameron AJ, Campbell KJ, Hesketh KD. Associations between the physical activity levels of fathers and their children at 20 months, 3.5 and five years of age. BMC Public Health. 2017;17:628.

84. Hnatiuk J, Salmon J, Campbell KJ, Ridgers ND, Hesketh KD. Early childhood predictors of toddlers' physical activity: longitudinal findings from the Melbourne InFANT program. Int J Behav Nutr Phys Act. 2013; 10:123.

85. Mei H, Johansson E, Hagströmer M, Xiong Y, Zhang L, Zhang J, Marcus C. Physical activity levels in Chinese one-year-old children and their parents, an early STOPP China study. PLoS One. 2016;11:e0153605.

86. Mackinnon DP, Fairchild AJ, Fritz MS. Mediation analysis. Annu Rev Psychol. 2007:58:593-614.

87. Downing KL, Hinkley T, Salmon J, Hnatiuk JA, Hesketh KD. Do the correlates of screen time and sedentary time differ in preschool children? BMC Public Health. 2017;17:285.

88. Chuang R-J, Sharma S, Skala K, Evans A. Ethnic differences in the home environment and physical activity behaviors among low-income, minority preschoolers in Texas. Am J Health Promot. 2013;27:270-8.

89. Tandon PS, Zhou C, Sallis JF, Cain KL, Frank LD, Saelens BE. Home environment relationships with children's physical activity, sedentary time, and screen time by socioeconomic status. Int J Behav Nutr Phys Act. 2012;9:88.

\section{Submit your next manuscript to BioMed Central and we will help you at every step:}

- We accept pre-submission inquiries

- Our selector tool helps you to find the most relevant journal

- We provide round the clock customer support

- Convenient online submission

- Thorough peer review

- Inclusion in PubMed and all major indexing services

- Maximum visibility for your research

Submit your manuscript at www.biomedcentral.com/submit 